\title{
The interactionism among nursing educators, preceptors and newly graduate nurses related to role transition: An exploratory study
}

\author{
Badriya M. Al-Riyami; Arlene V. Pamplona, Amal J. Al-Hadabi \\ Oman College of Health Sciences, South Batinah Governorate, Ministry of Health, Sultanate of Oman
}

Received: October 20, 2021

DOI: $10.5430 /$ jnep.v12n5p13
Accepted: December 2, 2021

Online Published: December 20, 2021

\begin{abstract}
Background and objective: The role transition remains a barrier in the ability of nurses to adjust from the role of student to professional nurse where the interactive mentoring attributes portrayed by nurse educators and clinical preceptors that may influence the role transition of new graduate nurses has not been thoroughly assessed. This study was conducted to explore the interactive mentoring attributes of nursing educators and clinical preceptors that influence new graduate nurses' ability to successfully adjust from the role of student to that of professional nurse.

Methods: Convergent parallel mixed method of research was used in this study, where both quantitative and qualitative data were simultaneously collected, analyzed, merged, compared and interpreted. The quantitative data came from purposively sampled first batch graduates of Bachelor of Science in Nursing at Oman College of Health Sciences A.Y. 2017-2018 $(\mathrm{N}=33$; $\mathrm{n}=27)$ through survey using researcher-made survey questionnaire in 5-point-Likert scale format based on the five attributes of beginning theory of Faculty Attributes for Confidence, Equilibrium, and Success (FACES) by Sparacino L. (2016). The qualitative exploration focused on the most significant influential interactive mentoring attributes of nursing educators and preceptors solicited through interview. Quantitative data were statistically treated and interpreted using percentage, weighted mean, $t$ test and Pearson's correlation. Qualitative data representing each participant's point of view were analyzed using open coding, transcribed, analyzed, compared, and categorized.

Results: Quantitative findings revealed that the respondents strongly agreed on the influential effect of interactive mentoring attributes portrayed by their preceptors in terms of professionalism while they agreed with their nursing educators (composite mean: 4.1 ; 3.9) respectively. Respondents also agreed with the influential effect of knowledge and experiences as well as in terms of care and rigor attributes. However, the $t$ test values and correlation analysis showed no significant relationship $(p>$ .05) between the profile of the respondents in terms of GPA and department with the interactive mentoring attributes portrayed by nursing educators and preceptors during role transition. Qualitatively, caring, rigor and professionalism were the significant interactive mentoring attributes of nursing educators and preceptors most influenced newly graduate nurses on their ability to successfully adjust from the role of student to that of professional nurse.

Conclusion and recommendation: The interactive mentoring attributes portrayed by nursing educators and preceptors have a positive influential effects in transition process, although the respondents' profile were not significantly related nor the relationship between the role portrayed by nursing educators and preceptors to role transition. Therefore, it is recommended to use these findings in curriculum revision and in the modification of clinical orientation or training policy.
\end{abstract}

Key Words: Transition role, Nursing educators, Clinical preceptors, New graduate nurses

*Correspondence: Badriya M. Al-Riyami; Email: alriyamibadriya@gmail.com; Address: Oman College of Health Sciences, South Batinah Governorate, Ministry of Health, Sultanate of Oman. 


\section{INTRODUCTION}

There remains an expectation within healthcare organizations that new graduate nurses should be able to "hit the ground running $\cdot{ }^{[-4]}$ This implies that new graduate nurses should be able to translate theory to practice as they transcend from the role of student nurse to professional nurse. During this transition stage, new graduate nurses often go through a period of high anxiety and stress as they adapt to the role of professional nurse. ${ }^{[5]}$ Despite the joint efforts of nursing faculty and preceptors to provide the necessary education to practice in todays- technologically advance and complex health-care system, and in developing comprehensive orientation program, the role transition remains a relevant barrier in the ability of many nurses to adjust from the role of student to professional nurse. Relative to transition issue, a recent study further mentioned that "one aspect of role transition that remains incompletely understood is the interactionism between nursing faculty and nursing student and its part in successful role transition". ${ }^{[5]}$ Thus, a deep understanding of the transition process that is rooted on the foundation of nursing education up to the initial stage of practicing the profession in terms of the important attributes portrayed by nursing educators and preceptors that may influence the role transition stage is deemed necessary with the hope of addressing the increasing transition dilemma.

In the aspect of understanding the deep sense of transition stage in reference to real-life experiences, pioneer studies used the term "reality shock" ${ }^{[6,12]}$ also known as role transition to describe the anxiety, doubt, and confusion nurses experience as they advance from the role of nursing student to professional nurse. While, one relevant study considered this role transition to cause $30 \%$ change of job among new nurses or they leave the profession within their first year of employment. ${ }^{[2]}$ This contribute much to the reported impending global nursing shortage, ${ }^{[7,8]}$ and impact on the low retention rates ${ }^{[9]}$ on the field of nursing and practice.

Repeated studies have been done to assess the ability of the new graduate nurses to adapt to the role of professional registered nurses since the concept of rule transition was introduced. ${ }^{[6]}$ Based on the current literature, several studies have shown how the health-care industry addresses the problem of reality shock. ${ }^{[10,11,13]}$ Various studies stated the successful preparation of students' entry into nursing profession in terms of student achievement, ${ }^{[14,15]}$ but very few studies thoroughly explore the role of nursing educators and preceptors from the perspective of the student preparing for the professional role. ${ }^{[14]}$ It is on this light that this study will be conducted. Since the bachelor of nursing program at Oman College of Health Sciences is still in its infancy stage as first batch has just deployed to governmental hospital for their post-graduate training, this study assessed the influential effect of the interactive mentoring attributes used by nursing educators and preceptors to the new graduate nurses' ability to successfully adjust from the role of student to that of professional nurse, based on the five attributes of beginning theory of FACES by. ${ }^{[5]}$ In addition, it seeks to identity significant differences between the interactive mentoring attributes used by nursing faculty and preceptors relative to role transition as perceived by the newly graduated nurses when they are grouped according to demographic profile. Furthermore, this study aimed to describe the significant interactive mentoring attributes of nursing educators and preceptors that influence new graduate nurses' ability to successfully adjust from the role of student to that of professional nurse when they were students and trainee.

The findings of this study sheds light on necessary attributes that allow nursing faculty and preceptors to lead by example as an aid to lessen the transition dilemma, get rid of the reality shock, strengthen confidence at work that facilitate new graduates' use of critical thinking and reasoning thereby successfully adjusting from the role of student to that of professional nurse. Moreover, this study serves as a guide for nursing educators and leaders in revising the curriculum content in the process of improving the standards of bachelor of nursing program and in the development of clinical orientation policy so that nursing graduates will be better able to meet the demand of the health-care industry.

\subsection{Research questions}

Specific research questions addressed were as follows:

1) What is the extent of the perceived influential effect of interactive mentoring attributes portrayed by nursing educators and preceptors as new graduate nurses transcend from the role of student to professional nurse in terms of five attributes of beginning theory of FACES such as knowledge, experience, caring, rigor and professionalism?

2) Is there a relationship between the interactive mentoring attributes portrayed by nursing educators and preceptors relative to role transition when respondent are grouped according to GPA and departments?

3) Is there a significant difference in the perceived influential effect of interactive mentoring attributes portrayed by nursing educators and preceptors relative to role transition?

4) What are the significant interactive mentoring attributes of nursing educators and preceptors that most influenced new graduate nurses' ability to successfully adjust from the role of student to that of professional nurse when they were students and trainees? 


\section{MeTHODS}

\subsection{Design}

The quantitative phase and qualitative exploration of this study assessed and described the influential effect of interactive mentoring attributes used by nursing educators and preceptors as new graduate nurses transcend from the role of student to professional nurse in terms of five attributes of beginning theory of FACES by ${ }^{[5]}$ as perceived by the newly

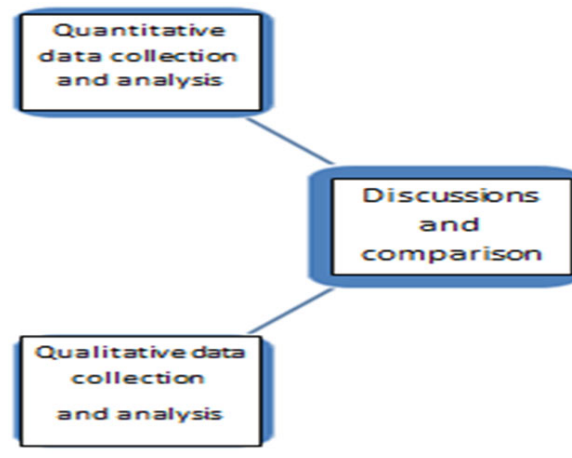

Figure 1. Research Process

\subsection{Sample}

Participants who met the following criteria participated on the study:

- Male and female first batch Bachelor of Science Nursing graduates at Oman College of Health Sciences, South Batinah Branch AY 2017-2018.

- Deployed and attended 6-month post-graduate training program at Rustaq General Hospital (1/4/2019-1/9/2019).

\subsubsection{Quantitative study group}

Purposive sampling was used to recruit the participants who meet the inclusion criteria and voluntarily agreed to participate on the study from the newly graduate first batch bachelor nursing students of Oman College of Health Sciences -South Batinah branch, last A.Y. 2017-2018 who are currently deployed at Rustaq General Hospital as the respondents of the study. Of the total population $(\mathrm{N}=33),(\mathrm{n}=27)$ voluntarily answered the online survey questionnaire.

\subsubsection{Qualitative study group}

Convenient sampling was used to recruit the participants for the qualitative part of the study. Of the total population ( $\mathrm{N}$ $=33),(n=13)$ participated into semi-structured face to face interview. All of the participants were female as none of the male graduates agreed to participate in the interview.

\subsection{Setting}

The study was conducted at Rustaq General Hospital, as one representative secondary hospital under the Ministry of Health in Oman who is in-charge of facilitating the trainings graduate first batch in bachelor nursing program.

With the purpose of corroboration and validation, the researchers aimed to triangulate the methods by directly comparing the quantitative statistical results and qualitative findings. In the research process, two datasets have been obtained, analyzed separately and compared. The research process as shown in Figure 1 followed the IPO (Input, Process, and Output) Model.

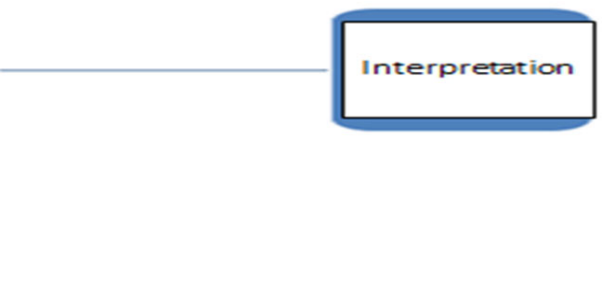

for all newly graduate nurses from Oman College of Health Sciences as the educational arm of the Ministry of Health.

\subsection{Data collection}

\subsubsection{Quantitative data collection tool}

Researcher-made survey questionnaire in 5-point-Likert scale format that was pilot tested and validated was used to collect the quantitative data needed on this study. Pilot study was carried out on $10 \%$ of the respondents and was validated by the two experts in the field of nursing education and health care institutions. Modifications were done on the questionnaire based on the pilot study findings using Cronbach's alpha for reliability of the instrument and content validity through the reports of expert faculty and preceptor. The questionnaire is consist of two parts, the first part solicited the demographic profile of the respondents. The second part made the respondents do self-assessment about the interactive mentoring attributes used by the nursing educators at Oman College of Health Sciences (South Batinah) and Rustaq General Hospital preceptors in assisting new bachelor graduate nurses' adjustment to practice their professional role and lessen the theory-practice gap in terms of five attributes of beginning theory of FACES.

The quantitative data were gathered from purposively sampled respondents in a period of two weeks (05-16 January 2021) after the approval of the research proposal by the RERAC -South Batinah and getting the consent to conduct the study from the Nursing Service Department of Rustaq 
Hospital. The online survey application link created by the researchers was emailed to the respondents together with the Informed Consent and Participation Information Sheet.

\subsubsection{Qualitative data collection tool}

In the qualitative stage, a structured face-to-face interview was used through the use of researchers' formulated guide questions in reference to the guide questions used in the formulation of FACES theory. ${ }^{[5]}$ Five guide questions where used for each group (nursing educator and preceptor) a total of ten to explore the significant interactive mentoring attributes of nursing educators and preceptors that influence new graduate nurses' on their ability to successfully adjust from the role of student to that of professional nurse.

Participant's interview were done in a period of two weeks to give ample time for the respondents to choose their most convenient schedule. Prior to the interviews, the study were explained, and verbal consent were obtained. Participants were also informed that the interviews would be recorded. All participants were assigned a study number to be used in the process of transcriptions which was accessed only by the researchers. Gathering of qualitative data stopped after achieving the data saturation.

\subsection{Data analysis}

Quantitative data were statistically interpreted to come up with the findings and results of the study. Percentage, ranking, weighted mean, $t$-test and correlation were used to assess the nursing educators and clinical preceptors interactive mentoring attributes at Oman College of Health Sciences (South Batinah ) and Rustaq General Hospital respectively, in assisting new bachelor graduate nurses' adjustment to practice.

Qualitative data representing each participant's point of view were analyzed using open coding steps by reading each interview more than once, and by continuously comparing data by the same researcher. The interviews were transcribed as well by the same researcher who repeatedly listened to the recorded interviews. The researcher coded the data, sentence by sentence to make sure there were no missing data. The codes were categorized under general title mainly related to the research objectives. General descriptive analysis of the categories were done based on research questions. Arabic to English translation were also done, the respondents felt more confident in expressing thoughts through Arabic language as the participants and the main researcher have the same Arabic native language. Related to translation process, the first researcher did the initial translation which was checked and finalized by a professional translator for back to back translation of sample interview transcripts. Furthermore, to ensure the credibility of results, an expert nurse educator reviewed the data.

\subsection{Ethical consideration}

The study was approved by the Research Ethical Review and Approval Committee (RERAC) of the Ministry of Health, South Batinah Governorate in Oman- (Ref. DGPS/Research Code 02032020 PROPOSAL APPROVAL 18/03/2020). In the study, informed consents were sought before the actual participation. Participants' information sheet was attached to the informed consent. It emphasized the volunteer participation of each respondent and that they have the right to decline from participation or to withdraw at any time. The study includes no harm for the subject's dignity, rights, and safety. The respondents' identities were kept confidential as questionnaires were left anonymous as it had no name. After data collection and retrieval, the data gathered were kept safely in one specified computer owned by the researcher and the data were shared only between the 3 researchers. The data file was kept for further analysis until the study is completed.

\section{RESULTS}

\subsection{Quantitative part}

The following are the data about the profile of the respondents who participated in this study, in terms of GPA and department or the place of work/training of the respondents not including the gender though it was part of the demographic profile but only one male participated on the quantitative study. Other data presented here are the perceived influential effect of the interactive mentoring attributes portrayed by nursing educators and preceptors in the role transition from student to professional nurse, the correlation between the profile and the interactive mentoring attributes as well as the relationship between the interactive mentoring attributes portrayed by nursing educators and preceptors relative to role transition as perceived by the new graduate nurses.

Table 1 presents the data of the department and GPA of the respondents. The data shows that out of 27 actual respondents, only 25 wrote the department or work place while only 20 of them voluntarily specified their Grade Point Average (GPA). As to department majority of them came from medicine while accident and emergency department was having the least participant comprising of $28 \%, 4 \%$ respectively. Most of the respondents achieved good GPA (3.25-3.74 or $\mathrm{B}+)$. This comprised more than half $(55 \%)$ percent of the total respondents. 
Table 1. Profile of the respondents based on Department and GPA

\begin{tabular}{llllll}
\hline Dept. & Freq & \% & GPA & Freq & \% \\
\hline ICU & 4 & 16 & $3.25-3.75\left(\mathrm{~B}^{+}\right)$ & 11 & 55 \\
Maternity & 6 & 24 & $3.0-3.24(\mathrm{~B})$ & 4 & 20 \\
A \& E & 1 & 4 & $2.75-2.99\left(\mathrm{~B}^{-}\right)$ & 4 & 20 \\
Medicine & 7 & 28 & $2.25-2.74\left(\mathrm{C}^{+}\right)$ & 1 & 5 \\
Surgery & 2 & 8 & & & \\
Pediatrics & 5 & 20 & & & \\
Total & 25 & 100 & & 20 & 100 \\
\hline
\end{tabular}

Table 2 shows that the respondents agreed they had used the knowledge they gained from their nursing educators to successfully adjust from the role of student to that of professional nurse. This was evident with the composite mean obtained of 3.9. Moreover, the highest among the indicators as to knowledge were the items on which it influence them were on having mastery of knowledge, portray intellectual level and increase power of inquiry and having state of the art skills in teaching with a weighted mean of 3.9. This meant that the respondents were able to grasp the theoretical knowledge needed to practice their profession. This further implied that they had a clear understanding about their chosen profession and that they believed that through the necessary knowledge they gained while attending their classes they were able to utilize it in bridging the gap between theory and practice during their transition stage.

Table 2. Respondents perceptions on the influential effect of interactive mentoring attributes portrayed by nursing educators and preceptors in the role transition from student to professional nurse in terms of Knowledge

\begin{tabular}{|c|c|c|c|c|}
\hline \multirow{3}{*}{ Indicators (Knowledge) } & \multicolumn{2}{|c|}{ Nurse Educators } & \multicolumn{2}{|l|}{ Preceptors } \\
\hline & Weighted & Verbal & Weighted & Verbal \\
\hline & Mean & Interpretation & Mean & Interpretation \\
\hline $\begin{array}{l}\text { a. Possess vast knowledge that reinforced my knowledge in } \\
\text { transition process }\end{array}$ & 3.6 & Agree & 3.7 & Agree \\
\hline $\begin{array}{l}\text { b. Have mastery of knowledge base theory content } \\
\text { simplification that stimulated my understanding of related } \\
\text { processes and principles during transition }\end{array}$ & 3.9 & Agree & 3.8 & Agree \\
\hline $\begin{array}{l}\text { c. Portray intellectual level and increase power of inquiry that } \\
\text { helped me understand, analyse related processes and } \\
\text { information in role transition }\end{array}$ & 3.9 & Agree & 3.7 & Agree \\
\hline $\begin{array}{l}\text { d. Having state of the art skills in teaching/mentoring that } \\
\text { helped me developed passion for learning in transition process }\end{array}$ & 3.9 & Agree & 3.6 & Agree \\
\hline Composite Mean & 3.9 & Agree & 3.7 & Agree \\
\hline
\end{tabular}

As shown in Table 3, the respondents agreed that the experiences they gained through their interactions with their nurse educators and preceptors helped them to successfully adjust from the role of student to that of professional nurse. This was evident with the composite mean of 3.8 and 3.7 respectively. In terms of the highest item rated under nurse educators, it was on the aspect of integrating personal experiences into teaching, with a weighted mean of 4.1 and was further verbally interpreted as strongly agree while under preceptors side respondents agreed that sharing real-life case studies/patient case scenario made the respondents translate the gained knowledge and skills into practice in role transition and it ranked the most with a weighted mean of 3.8. Mostly, the respondents strongly agreed that through integration of personal experience into teaching helped them improved their ability to conceptualize and build confidence during transition process as well as through sharing of reallife case studies. The experiences related to the use of multiple technological venues in classroom and teaching beyond

Published by Sciedu Press the content of what is needed ranked least among the four indicators related to experience, though respondents also showed agreement that both are likewise important in enhancing their critical capabilities, apply reasoning skills in high pressure situation and that it should be taken into consideration as well.

In terms of caring attributes, Table 4 shows that the respondents agreed on the influential effect of interactive mentoring attributes portrayed by nursing educators and preceptors in the role transition from student to professional nurse. This was evident with the obtained composite mean of 3.7. As to the highest items which obtained a weighted mean of 3.8 for both groups were related on setting as an example of being compassionate and in the integration of kind and positive approach in teaching, enticed the respondents to deliver utmost care to the patient during transition process. Hence, it could be gleaned that the respondents believed that they had developed the caring attitude through the influence of their nurse educators and preceptors. 
Table 3. Respondents perceptions on the influential effect of interactive mentoring attributes portrayed by nursing educators and preceptors in the role transition from student to professional nurse in terms of Experience

\begin{tabular}{|c|c|c|c|c|}
\hline \multirow{3}{*}{ Indicators (Experience) } & \multicolumn{2}{|c|}{ Nurse Educators } & \multicolumn{2}{|l|}{ Preceptors } \\
\hline & Weighted & Verbal & Weighted & Verbal \\
\hline & Mean & Interpretation & Mean & Interpretation \\
\hline $\begin{array}{l}\text { a. Integrate personal experiences into teaching/mentoring } \\
\text { that helped me conceptualized and built confidence during } \\
\text { transition process }\end{array}$ & 4.1 & Strongly Agree & 3.7 & Agree \\
\hline $\begin{array}{l}\text { b. Share real-life case studies/patient case scenario that } \\
\text { made me translate the gained knowledge and skills into } \\
\text { practice in role transition }\end{array}$ & 3.9 & Agree & 3.8 & Agree \\
\hline $\begin{array}{l}\text { c. Incorporate the use of multiple technological venues in } \\
\text { classroom/mentoring that helped me critically evaluate } \\
\text { related and technology based information in role transition. }\end{array}$ & 3.5 & Agree & 3.7 & Agree \\
\hline $\begin{array}{l}\text { d. Taught not only content but how to use critical thinking } \\
\text { and apply reasoning skills in high pressure situation that } \\
\text { permitted me to offer concrete explanations based on } \\
\text { evidence during role transition. }\end{array}$ & 3.5 & Agree & 3.6 & Agree \\
\hline Composite Mean & 3.8 & Agree & 3.7 & Agree \\
\hline
\end{tabular}

As shown from Table 5, respondents agreed on rigorous attitude portrayed by nursing educators and preceptors and have influential effect in the role transition from student to professional nurse with a weighted mean of 3.6 and 3.7 respectively. The highest item rated for both groups were on the item related to personal grooming and physical appearance. A routine strict implementation on these aspect starting from their college days up to their clinical trainings helped the respondents look good in spite of the challenging task during transition process. Strict and always adhere to rigor in policies without exception was ranked lowest under the influence of educators while enforced rules on case to case basis with minimal strictness on policies were the lowest rated item under the influence of preceptors. This extreme results between the two groups have a great influence in maintaining a calm attitude while working under pressure during transition process.

Table 4. Respondents perceptions on the influential effect of interactive mentoring attributes portrayed by nursing educators and preceptors in the role transition from student to professional nurse in terms of caring attributes

\begin{tabular}{|c|c|c|c|c|}
\hline \multirow{3}{*}{ Indicators (Caring) } & \multicolumn{2}{|c|}{ Nurse Educators } & \multicolumn{2}{|c|}{ Preceptors } \\
\hline & Weighted & Verbal & Weighted & Verbal \\
\hline & Mean & Interpretation & Mean & Interpretation \\
\hline $\begin{array}{l}\text { a. Portray caring attitude in teaching made me feel comfortable in } \\
\text { seeking help when needed in role transition. }\end{array}$ & 3.7 & Agree & 3.8 & Agree \\
\hline $\begin{array}{l}\text { b. Set as an example of being compassionate helped me delivered } \\
\text { utmost care to my patient during transition process. }\end{array}$ & 3.8 & Agree & 3.8 & Agree \\
\hline $\begin{array}{l}\text { c. Integrate kind and positive approach in teaching/mentoring } \\
\text { developed in me the appreciation and importance of my duty } \\
\text { during transition process. }\end{array}$ & 3.8 & Agree & 3.6 & Agree \\
\hline $\begin{array}{l}\text { d. Show a deep sense of understanding and wide range of } \\
\text { consideration in all aspects of life helped me in moulding my } \\
\text { personality during role transition }\end{array}$ & 3.6 & Agree & 3.6 & Agree \\
\hline Composite Mean & 3.7 & Agree & 3.7 & Agree \\
\hline
\end{tabular}

Table 6 shows that respondents strongly agreed on the influential effect of interactive mentoring attributes portrayed by their preceptors in terms of professionalism while they agreed with their nursing educators, having a composite mean of
4.1 and 3.9 respectively. The importance of personal look on the overall physical appearance that showed professionalism at work during transition process was the highest item rated for both groups while the lowest item rated for both groups 
was on the item related to maintaining a professional tone rity in handling uncontrollable situations at work while on of voice and actions in all circumstances as a sense of matu- transition process.

Table 5. Assessment of the Respondents perceptions on the influential effect of interactive mentoring attributes portrayed by nursing educators and preceptors in the role transition from student to professional nurse in terms of Rigor

\begin{tabular}{|c|c|c|c|c|}
\hline \multirow{3}{*}{ Indicators (Rigor) } & \multicolumn{2}{|c|}{ Nurse Educators } & \multicolumn{2}{|l|}{ Preceptors } \\
\hline & Weighted & Verbal & Weighted & Verbal \\
\hline & Mean & Interpretation & Mean & Interpretation \\
\hline $\begin{array}{l}\text { a. Strict and always adhere to rigor in policies without exception } \\
\text { developed in me self-discipline at work during transition process. }\end{array}$ & 3.3 & Agree & 3.7 & Agree \\
\hline $\begin{array}{l}\text { b. Routinely enforce rules on assigned tasks and punctuality that } \\
\text { developed in me the value of commitment while working with } \\
\text { my department during transition stage. }\end{array}$ & 3.6 & Agree & 3.7 & Agree \\
\hline $\begin{array}{l}\text { c. Routinely check and enforce strict rules on personal grooming } \\
\text { and uniforms molded my physical appearance to look good } \\
\text { during transition process. }\end{array}$ & 3.9 & Agree & 3.9 & Agree \\
\hline $\begin{array}{l}\text { d. Enforce rules on case to case basis with minimal strictness on } \\
\text { policies developed in me a calm attitude while working under } \\
\text { pressure during transition process. }\end{array}$ & 3.5 & Agree & 3.6 & Agree \\
\hline Composite Mean & 3.6 & Agree & 3.7 & Agree \\
\hline
\end{tabular}

Table 6. Respondents perceptions on the influential effect of interactive mentoring attributes portrayed by nursing educators and preceptors in the role transition from student to professional nurse in terms of Professionalism

\begin{tabular}{|c|c|c|c|c|}
\hline \multirow{3}{*}{ Indicators (Professionalism) } & \multicolumn{2}{|c|}{ Nurse Educators } & \multicolumn{2}{|c|}{ Preceptors } \\
\hline & Weighted & Verbal & Weighted & Verbal \\
\hline & Mean & Interpretation & Mean & Interpretation \\
\hline $\begin{array}{l}\text { a. Portray a sense of professionalism in all situations } \\
\text { developed in me the idea of being a professional at work } \\
\text { during transition process. }\end{array}$ & 4.0 & Agree & 4.2 & Strongly Agree \\
\hline $\begin{array}{l}\text { b. Show professionalism on physical appearance reminds me } \\
\text { of the importance of personal look when at work during } \\
\text { transition process. }\end{array}$ & 4.1 & $\begin{array}{l}\text { Strongly } \\
\text { Agree }\end{array}$ & 4.3 & Strongly Agree \\
\hline $\begin{array}{l}\text { c. Maintain a professional tone of voice and actions in all } \\
\text { circumstances developed in me a sense of maturity in handling } \\
\text { uncontrollable situations at work while on transition process. }\end{array}$ & 3.7 & Agree & 4.0 & Agree \\
\hline $\begin{array}{l}\text { d. Maintain student bond of friendship during educational } \\
\text { experience taught me the value of collaboration and good } \\
\text { relationship at work during role transition. }\end{array}$ & 3.9 & Agree & 4.0 & Agree \\
\hline Composite Mean & 3.9 & Agree & 4.1 & Strongly Agree \\
\hline
\end{tabular}

Table 7 shows the correlation between the profile of the respondents and the interactive mentoring attributes portrayed by nursing educators and preceptors relative to role transition as perceived by the new graduate nurses. All the $p$ values are higher than .05 . Therefore it can be concluded that there is no significant relationship between the respondent's profile in terms of GPA and department with the interactive mentoring attributes portrayed by nursing educators and preceptors during role transition process.
Table 8 shows that there was no significant relationship between the interactive mentoring attributes portrayed by nursing educators and preceptors relative to role transition as perceived by the new graduate nurses. Paired sample $t$-test values showed no significant relationship which was higher than the critical value of .05. Then, the formulated research question no. 3 as an interrogatively statement for null hypothesis was accepted. 


\subsection{Qualitative findings}

This section discusses the themes emerged from the analysis regarding the role of nursing educators and preceptors in the transition process of nursing students to their professional role.

Table 7. Correlation between the profile and the interactive mentoring attributes portrayed by nursing educators and preceptors relative to role transition as perceived by the new graduate nurses

\begin{tabular}{lllllll}
\hline \multirow{2}{*}{ Attributes } & Pearson's $\boldsymbol{r}$ & & & $\boldsymbol{p}$ value & & \multirow{2}{*}{ Verbal Interpretation } \\
\cline { 2 - 3 } & GPA & Dept. & & GPA & Dept. & \\
\hline Knowledge & 0.029 & 0.020 & & 0.902 & 0.973 & Not Significant \\
Experience & 0.295 & 0.008 & & 0.206 & 0.973 & Not Significant \\
Caring & 0.255 & 0.266 & & 0.278 & 0.256 & Not Significant \\
Rigor & 0.004 & -0.049 & & 0.986 & 0.838 & Not Significant \\
Professionalism & 0.134 & 0.022 & & 0.574 & 0.925 & Not Significant \\
\hline
\end{tabular}

Table 8. Relationship between the interactive mentoring attributes portrayed by nursing educators and preceptors relative to role transition as perceived by the new graduate nurses

\begin{tabular}{lllllll}
\hline Attributes & $\begin{array}{l}\text { Mean (Nursing } \\
\text { Educators) }\end{array}$ & $\begin{array}{l}\text { Mean } \\
\text { (Preceptors) }\end{array}$ & $\begin{array}{l}\text { Paired Sample } \\
\boldsymbol{t} \text {-test Value }\end{array}$ & Df & $\boldsymbol{p}$ value & $\begin{array}{l}\text { Verbal } \\
\text { Interpretation }\end{array}$ \\
\hline Knowledge & 3.850 & 3.778 & 0.437 & 17 & .668 & Not Significant \\
Experience & 3.800 & 3.889 & 0.718 & 17 & .483 & Not Significant \\
Caring & 3.850 & 3.833 & 0.000 & 17 & 1.000 & Not Significant \\
Rigor & 3.750 & 3.833 & 1.000 & 17 & .331 & Not Significant \\
Professionalism & 4.050 & 4.000 & 0.000 & 17 & 1.000 & Not Significant \\
\hline
\end{tabular}

\subsubsection{Knowledge and experience}

Knowledge and experience were substantive themes that emerged in this study. Respondents identified several learning strategies used by their faculty which included but were not limited to, lecturing, concept mapping, cooperative learning, games, debate, and clinical experiences, as an effective ways to mimic patient care environment and apply the gained theoretical knowledge. Respondents also highlighted that during the course of their study and internship their vast experience with these learning strategies helped them to express their ideas and enhanced their ability to analyze, evaluate, and think critically thereby understanding the interrelationships between the different aspects of the same topic. Participant 4 stated "being engaged in cooperative learning for example, was useful in preparing us for the transitional role as a nurse where the team work is considered the essence in nursing role". Relatively, respondents correlated the knowledge of their faculty and preceptors with their experiences as they have been practicing their profession for almost a decade already.

\subsubsection{Caring}

The third theme the respondents emphasized through their various statements was caring. Majority mentioned that throughout their study years and internship period, in several moments, especially during their clinical practice and community projects, they felt lack of confident. However, their nursing faculty and preceptors were always standing behind them, encouraging them, and helping them to see more of their strengths. On the other hand, due to lack of individual differences among various students was one of the common points raised in this study. Another issue raised by several graduates was that some of senior nurses regarded them as students and that they don't treat them as colleagues. According to the respondents they expected their preceptors to talk to those nurses and try to do something regarding this issue, however, several preceptors did nothing about it. Participants 5 said "in such circumstances, I was in need of my preceptor, but I felt I was left alone..."

\subsubsection{Professionalism}

Faculty were viewed as role models in regards to knowledge, skills, attitudes and behaviors. Theoretical classes were seen as a great venue where students/graduates can grow professionally as they were taught on how to practice the lifelong learning which they believe as the core of their nursing career. However, the lack of using research findings and up-to-date information specifically by the preceptors was a major hindrance. Relatively, more than half of graduates mentioned that their faculty utilized research during their theory and laboratory sessions and while discussing patients conditions in various clinical settings to upgrade 
and update their professional knowledge and skills qualifications. This in turn motivates the respondent to do the same. Attending various nursing and medical forums as well as community activities were significant useful too. In addition, although less than half of the respondents mentioned that their faculty were good listener to them, this positive professional behavior instilled in them the importance of attentive listening and they learned to be good listeners as well. Furthermore, respondents also reported that their preceptors and faculty's commitment to the nursing code of conduct were well manifested in presenting themselves as role models for their students. Most of them mentioned that they learned from their preceptors how to react, act professionally with the health team, while dealing and talking to the patients such as using eye contact, voice tone and respectful manners. Knowing such things, several respondents said that their preceptors encouraged and helped them to achieve the unit aim and to implement healthy and safety management to patients. Moreover, most respondents said that nursing educators and preceptors emphasized a lot on the importance of knowing and understanding their rights and duties along with their patient's rights which plays huge impact in maintaining professionalism at work.

Lastly, various behaviors displayed by nurse educators and preceptors nurtured the respondents to become professional practitioners showing, motivation, support, trust, coaching, effective listening and having faith on the them that they are going to be a good professional practitioners. Nursing educators and preceptors were viewed as a source of strength, reassurance and knowledge whom they can depend on.

\subsubsection{Rigor}

The way their nursing educators were dealing with graduates during the clinical practice played the major role in increasing their confidence and therefore facilitate their transition to nursing role. According to them, their faculty provide them the space as much as they could of how they are going to act.

Several respondents said that their nursing educators dealt with them as a staff nurse during the fourth year of nursing study specifically during their comprehensive practicum course while many respondents mentioned that their preceptors trained them on how to take care of a group of patients independently. Such behavior and interactions they believe helped them to work independently, and enhance their confidence in dealing with patients, nurses and other healthcare professional. They found this behavior important in understanding the demands of the profession they are soon going to be part of.

However, several respondents mentioned that the continuous orientation and discussion of patient's cases were the

Published by Sciedu Press most important behavior that enhanced their confidence and strengths. Moreover, being mentored by preceptors whom they believed are knowledgeable, skillful and strictly following the rules and policies also played a major role in enhancing their professional confidence. On the other hand, several respondents said that being taught and supervised by a very strict nurse educators and preceptor did not always facilitated their learnings as they were afraid of doing mistakes, thereby affecting their self-confidence. However, many of them affirmed that after graduation and while working as a staff nurse, they understood the importance of being trained by a nurse educators who were strict with them with regards to time, uniform, hospital rules and policies.

\section{Discussions}

Based on the findings related to knowledge, the respondents saw clearly and comprehensively the importance of acquiring the necessary theoretical knowledge in the classroom as delivered by their nurse educators and the shared knowledge by their preceptors in bridging the gap between theory and practice during their transition stage. The results of the qualitative interview related to this aspect described that nursing faculty and preceptors used mixed strategies in teaching and orienting the respondents in order to help them to prepare for their professional role.

These findings are supported by the previous study who defines theory-practice gap as discrepancy between what students acquire through theoretical classroom lectures and what they experience in the clinical setting. ${ }^{[16]}$ Although the expectation is that nursing theory should provide the basis for understanding nursing reality in practice, it is acknowledged from the literature the evidences emerging from transition into professional practice that undergraduate students experience a disconnection between what they learnt in theory and what is obtainable in practice. This was reinforced in another related study who argued that theory-practice gap emerges when theory is not translated into action. ${ }^{[17]}$ While based on the investigation on the phenomenon of theory-practice gap from the perspectives of three user groups -students, nurse educators and clinical preceptors, all these three groups identified the existence of dichotomy between nursing theory as taught in the classroom and professional nursing practice as enacted at the bedside. ${ }^{[18]}$ Truly, knowledge attributes plays an important aspect in the transition process.

Findings related to experiences suggest that the respondents were able to be helped by the so called 'experience is the best teacher" in terms of conceptualization of concrete explanations and reasoning skills during role transition based on the shared experience of their nurse educators. Through shared experiential knowledge, respondents were also able to build 
confidence and translate the gained skills into practice in role transition. As posited in the previous study the foundation of nursing knowledge starts at nursing school. ${ }^{[16]}$ This study further implied that nurses prefer to use the knowledge that they gained out of their four long years of stay at school where nurse educator share experiential knowledge that is characterized by a high degree of conviction in its potential to impact the practice of nurses and the patients outcome. Thus, shared experiential knowledge act as a link liaising practitioners to the most up-to-date evidences and should be perceived as real learning rather than just knowledge integration.

Hence, the findings on the ability of the respondents to increase their skills through shared experiential knowledge are supported by the findings of several researches conducted by the scholars. This aspect was confirmed not only quantitatively but was being described verbally based on the respondents' statements during the interview. Respondents affirmed that their nurse educators and preceptors possess vast knowledge which were unselfishly shared with them. They conveyed their admiration for the numerous strategies used by their nursing educators and preceptors, which facilitated their knowledge acquisition and understanding. Having been taught and guided by a well informed and experienced educators and preceptors have contributed much to overcome the challenges during their transition process which testify to the soundness of the influential impact of experience as one important attributes in the role transition.

The findings related to caring attributes implied that this attitude portrayed by their teachers and preceptors helped them to develop a kind attitude as well. The respondents also learned to integrate compassionate care to patients and appreciate the importance of commitment to duty during transition process. This positive attitude once again proved by the respondents as an important aspect of the influential attributes needed to successfully lessen the dilemma of role transition. It was also evident that this attributes helped them to collaborate with their colleagues not only in the classroom, not only in the nurse stations but most of all in giving beyond care while in the patients' room. On the other hand, the results of the interview on this aspect stressed that some nurse educators, preceptors and senior staff nurses were not supportive which inhibited their ability to successfully adjust to the role of professional nurse.

Relatively, as found out on the recent study, New Practicing Nurses (NPN) frequently experience the limitations of stress and overload which is incongruous with experiencing holistic comfort during their education. ${ }^{[19]}$ This study further mentioned that a NPN who experiences holistic comfort is more likely to be comforting to their patients. Consequently, if student nurses experience holistic comfort throughout their education, it can be anticipated that they may be more authentically comfortable as they transcend into practice. Being more comfortable with managing the realities of nursing practice by seeking the support and mentoring, is exemplary necessary during transition process, as newly graduate nurses may also be more comforting to patients, peers and future nurses in the profession. This was reinforced by another study who found a high rate of turnover in recent nursing graduates due to stress, frustration and lack of support. ${ }^{[10]}$ Thus, holistic comfort and caring attitude embedded into nursing education program offers a novel approach in preparing future nurses from the outset of a potentially challenging career. To be aware not just of the meaning of holistic comfort, but of experiencing it so it may be relived in others, is part of the self-becoming of a nurse, ${ }^{[20]}$ as one important aspect of role transition. Moreover, a caring preceptors team helps create a positive working relationships with the graduates enabling them to not only feel part of the team but also feel emotionally supported. ${ }^{[13]}$

Quantitative and qualitative findings revealed that rigor portrayed by nursing educators and preceptors have influential effect in the role transition from student to professional nurse. Students are affected in a negative way when teachers are in control of the learning process. ${ }^{[21]}$ In this setting, students are uncomfortable expressing thoughts, ideas and feelings. This is precisely what scholars have written in the literature describing a progressive teaching as a way to eradicate fear in the learning environment. On the other hand, a learnercentered teaching requires a distribution of power away from the educator and toward the learner, but meeting somewhere in the middle so that students are more motivated and empowered to be actively engaged in their own education. ${ }^{[21]}$ Similarly, findings from previous studies suggests that there is a need to do some deconstruction of the traditional perception that the teacher is solely responsible for the education of the student. Current literature advocates a holistic framework for a democratic and dynamic learning experience in which both student and teacher are engaged in a reciprocal learning partnership. This concept could be applied in preparing new nurses so that they are not simply engaged in gathering a plethora of information and acquiring a repertoire of technical skills, but are truly learning in an environment of holistic comfort without fear.

Respondents confirmed professionalism and unprofessionalism behavior of some nursing faculty which can greatly influenced them to act and become professional practitioners. Related data about this aspect revealed that nursing is not an easy profession, but tough, tiring and hectic one. Nevertheless, respondents' appreciation of their mentors were 
clearly emphasized in this study. Even though nursing is a demanding career respondents assured that during their years of nursing study, they were trained and shaped to face the demand of their profession. Respondents valued their nurse educators who was more friendly with them. Moreover, nurse educators and preceptor's availability and accessibility were also a great help for them, which can lessen the work related-stress most especially during challenging situation.

Relatively, as mentioned from the literature, students seek an appropriate role model at school in order to adopt values, attitudes and behaviors. As a consequence, they experience an integration as a member of the profession. ${ }^{[22]}$ Moreover, when the educational environment supports both learning and creativity, students make observation and acquire a range of qualifications that are evaluated within the scope of professional identity, such as communication skills, problemsolving, prediction and decision-making skills. ${ }^{[23]}$ However, the process of being a participant and observer within the realities of the clinical environment during the role transition completes the professional identity as well as the development of the student nurse into a young professional. ${ }^{[24]}$ Thus, nurse educators and preceptors have the responsibility to be a role model while training them, in terms of their actions, intellectual and caregiver roles as an important aspect in role transition. Likewise, the qualitative findings of this study also acknowledge nurse educators and preceptors' behaviors and attitudes guided the graduates when working in health care settings as professionals.

The non-significant relationship that existed between the profile of the respondents in terms of GPA and department and on how the respondents perceived the mentoring attributes portrayed by nurse educators and preceptors relative to role transition was indeed evident with the findings that when the student nurses are being nurtured holistically as shown from having good GPA during their nursing education, no matter what department they will be assigned after gaining their degree will not be a hindrance for them to assumed the role of an advance beginner nurse practitioner. This was supported by the recent study who mentioned that both academic and nursing administration team members can play key roles in facilitating a smooth transition and the integration of new nurses into the nursing workforce through the employment of evidence-based educational and structured organizational strategies. ${ }^{[25]}$

Although the phenomenon of reality shock has been acknowledged as part of the new graduate nurse transition for decades, the non-significant findings of this study between the role portrayed by nursing educators and preceptors related to role transition suggest that the problems with the transition into

Published by Sciedu Press practice can be resolved through proper coordination and alignment of the course requirements with what is actually needed in the medical field, thereby bridging the gap between theory and practice. This was reinforced by the recent study on which the findings revealed that the expectations and understandings of new graduate practice readiness were influenced by the historical and social context within which nursing education and professional practice is grounded. ${ }^{[26]}$ These differences centered around three main areas: the educational preparation of nurses (diploma or degree), the preparation of the technical versus the professional nurse, and the perceived responsibilities and accountabilities of the education and practice sector for the educational preparation of nurses. To shift the discourse around practice readiness, this study further mentioned that nurses from all sectors must focus on unique, innovative and cooperative solutions to ensure the seamless transition of all nursing graduates in the 21 st century healthcare system.

\section{CONCLUSIONS AND RECOMMENDATIONS}

The findings of this study sheds light on the influential attributes portrayed by nurse educators and preceptors related to role transition. Based from the foregoing findings, it was concluded that majority of the respondents were having good academic standing, and were deployed into several departments in the hospital. Although the respondents' profile were not significantly related to the influential interactive mentoring attributes portrayed by nursing educators and preceptors it has been concluded to have a positive influential effects to the respondents as they transcend from the role of student to professional nurse in terms of five attributes of beginning theory of FACES such as knowledge, experience, caring, rigor and professionalism. Furthermore, the non-significant findings of this study between the role portrayed by nursing educators and preceptors doesn't matter as long as these two key players do their part in bridging the gap between theory and practice and continuously lead by example as an aid to lessen the transition dilemma, get rid of the reality shock, strengthening confidence at work which can facilitate new graduates' use of critical thinking and reasoning in order to successfully adjust from the role of student to that of professional nurse.

Therefore, it is highly recommended that due to the intense yet dynamic transition experience, these newly graduates nurse assessment should inspire educational and service institutions to further enhance and continuously provide preparatory education on transition. Additionally, an extended, sequential, and structured orientation and mentoring programs that can help bridge nursing graduates' expectations of professional work life with the reality of employment is highly 
recommended as well. Moreover, the findings of this study can also be used as a guide for nursing educators and clinical preceptors in revising the curriculum content in the process of improving the standards of bachelor nursing program and in the modification of clinical orientation and training policy so that nursing graduates not only successfully adjust from the role of student to that of professional nurse, thereby become a globally competitive nursing graduates who can confidently perform and meet the demand of health-care industry.

\section{Limitations of the study}

Limitations of the study can be associated to the limited data due to the number of participants and the convenience of the sample. The small sample size may not allow the information to be generalizable to other educational settings. Greater strength can be applied to the findings when similar data is collected from larger studies. Most of the participants were females which may post gender-mixed view bias.

\section{ACKNOWLEDGEMENTS}

The researchers would like to acknowledge Bachelor of Science in Nursing students, Batch 2018 at Oman College of Health Sciences and currently employed at Rustaq General Hospital for their active participation as the respondents of the study.

\section{CONFLICTS OF INTEREST DisClOSURE}

The authors declare that there is no conflict of interest.

\section{REFERENCES}

[1] Boamah S, Read E, Laschinger H. Factors influencing new graduate nurse burnout development, job satisfaction and patient care quality: a time-lagged study. J. Adv. Nurs. 2016; 73(5): 1182-1195. PMid:27878844 https://doi.org/10.1111/jan.13215

[2] Walker A, Costa B, Foster A, et al. Transition and integration experiences of Australian graduate nurses: A qualitative systematic review. Collegian. 2017; 24(5): 505-512. https://doi.org/10.1016/j colegn.2016.10.004

[3] Missen K, McKenna L, Beauchamp A, et al. Qualified nurses' rate new nursing graduates as lacking skills in key clinical areas. J. Clin. Nurs. 2016; 25(15-16): 2134-2143. PMid:27301654 https://doi.org/10.1111/jocn.13316

[4] Regan S, Wong C, Laschinger H, et al. Starting Out: qualitative perspectives of new graduate nurses and nurse leaders on transition to practice. J. Nurs. Manag. 2017; 25(4): 246-255. PMid:28244181 https://doi.org/10.1111/jonm.12456

[5] Sparacino L. Faculty's Role in Assisting New Graduate Nurses' Adjustment to Practice. 2016. https://doi .org/10.1177/237796 0816635182

[6] Kramer M. Reality shock: Why nurses leave nursing. St.Louis, MO: Mosby. 1974.

[7] Shamsi A, Peyravi H. Nursing shortage, a different challenge in Iran: A Systematic Review. Med J Islam Repub Iran. 2020; 34(8). https://doi.org/10.34171/mjiri.34.8

[8] Liu J, Goryakin Y, Maeda A, et al. Global health workforce labor market projections for 2030. Hum. Resour. Health. 2017; 15(1). PMid:28159017 https://doi .org/10.1186/s12960-017-018 7-2

[9] Wakefield E. Is your graduate nurse suffering from transition shock? Journal of Perioperative Nursing. 2018; 31(1): 47-50. https ://do i. org $/ 10.26550 / 311 / 47-50$

[10] Dahlke S, OConnor M, Hannesson T, et al. Understanding clinical nursing education: An Exploratory study. Nurse Education in Practice. 2016; 17: 145-152. PMid:26775165 https ://doi .org/10.1 016/j.nepr. 2015.12.004

[11] Lafrance T. Exploring the intrinsic benefits of nursing preceptorship: A personal perspective. Nurse Education in Practice. 2018; 33: 1-3.
PMid:30212739 https://doi.org/10.1016/j.nepr.2018.08 .018

[12] Doughty L, McKillop A, Dixon R, et al. Educating new graduate nurses in their first year of practice: The perspective and experiences of the new graduate nurses and the director of nursing. Nurse Education in Practice. 2018; 30: 101-105. PMid:29698878 https://doi.org/10.1016/j.nepr.2018.03.006

[13] Wakefield E. Is your graduate nurse suffering from transition shock? Journal of Perioperative Nursing. 2018; 31(1). https : //doi .org/ 10.26550/2209-1092.1024

[14] Benner PE, Sutphen M, Leonard V, et al. Educating nurses: A call for radical transformation. SanFrancisco, CA: Jossey-Bass. 2010.

[15] Billings DM, Halstead JA. Teaching in nursing: A guide for faculty. 4th ed. St. Louis, MO: Elsevier/Saunders. 2012.

[16] Hussein MT, Osuji J. Bridging the theory-practice dichotomy in nursing: The role of nurse educators. Journal of Nursing Education and Practice. 2016; 7(3): 20. https://doi.org/10.5430/jnep.v7n 3 p20

[17] Risjord M. Nursing knowledge: Science, practice and philosophy. Oxford, United Kingdom: Wiley-Blackwell. 2010.

[18] Salifu D, Gross J, Salifu M, et al. Experiences and perceptions of the theory-practice gap in nursing in a resource-constrained setting: A qualitative description study. WILEY NursingOpen. 2019; 6: 72-83. PMid:30534396 https://doi.org/10.1002/nop2.188

[19] Labrague L, McEnroe-Petitte D, Gloe D, et al. A literature review on stress and coping strategies in nursing students. Journal of Mental Health. 2016 Dec. PMid:27960598 https://doi .org/10.1080/ 09638237.2016 .1244721

[20] Benner P. From novice to expert. Am. J. Nurs. 1984; 82(3): 402. https://doi.org/10.2307/3462928

[21] Weimer M. Learner-Centred Teaching: Five Key Changes to Practice. San Francisco, CA: Jossey-Bass. 2002.

[22] Poorchangizi B, Farokhzadian J, Abbaszadeh A, et al. The importance of professional values from clinical nurses' perspective in hospitals of a medical university in Iran. BMC Med ethics. 2017; 18(1): 20 PMid:28249603 https ://doi .org/10.1186/s12910-017-017 8-9

[23] Thomson R, Docherty A, Duffy R. Nursing students' experiences of mentorship in their final placement. BJN. 2017; 26(9). 
PMid:28493780 https://doi.org/10.12968/bjon.2017.26. 9.514

[24] Mlambo M, Silen Ch, Mcgrath C. Lifelong learning and nurses' continuing professional development, a Metasynthesis of the literature. BMC Nursing. 2021; 20: 62. PMid:33853599 https: //doi.org/10.1186/s12912-021-00579-2

[25] Labrague LJ, McEnroe-Pettite D, Leocadio MC. Transition experi- ences of newly graduated Filipino nurses in a resource-scarce rural health care setting: A qualitative study. Nurse Forum. 2019 Apr; 54(2): 298-306. PMid:30775787 https://doi .org/10.1111/nu f. 12330

[26] Mirza N, Rankin L, Prentice D, et al. Practice readiness of new nursing graduates: A concept analysis. Nurse Educ Pract. 2019 May; 37: 68-74. PMid:31112923 https://doi.org/10.1016/j.nepr .2019 .04 .009 